Please do not remove this page

RMIT

UNIVERSITY

\title{
Simulation-based evaluation of defuzzification-based approaches to fuzzy multi-attribute decision making
}

Deng, Hepu; Yeh, Chung-Hsing

https://researchrepository.rmit.edu.au/esploro/outputs/9921859887801341/filesAndLinks?institution=61RMIT_INST\&index=null

Deng, H., \& Yeh, C.-H. (2006). Simulation-based evaluation of defuzzification-based approaches to fuzzy multi-attribute decision making. IEEE Transactions on Systems, Man and Cybernetics: Part A-Systems and Humans, 36(5), 968-977. https://doi.org/10.1109/tsmca.2006.878988

Published Version: https://doi.org/10.1109/tsmca.2006.878988

Repository homepage: https://researchrepository.rmit.edu.au

(c) 2006 IEEE. Personal use of this material is permitted. However, permission to reprint/republish this material for advertising or promotional purposes or for creating new collective works for resale or redistribution to servers or lists, or to reuse any copyrighted component of this work in other works must be obtained from the IEEE.

Downloaded On 2023/04/26 20:07:41 +1000 


\title{
Simulation-Based Evaluation of Defuzzification-Based Approaches to Fuzzy Multiattribute Decision Making
}

\author{
Hepu Deng and Chung-Hsing Yeh, Senior Member, IEEE
}

\begin{abstract}
This paper presents a simulation-based study to evaluate the performance of $\mathbf{1 2}$ defuzzification-based approaches for solving the general fuzzy multiattribute decision-making (MADM) problem requiring cardinal ranking of decision alternatives. These approaches are generated based on six defuzzification methods in conjunction with the simple additive weighting (SAW) method and the technique for order preference by similarity to the ideal solution method. The consistency and effectiveness of these approaches are examined in terms of four new objective performance measures, which are based on five evaluation indexes. The simulation result shows that the approaches, which are capable of using all the available information on fuzzy numbers effectively in the defuzzification process, produce more consistent ranking outcomes. In particular, the SAW method with the degree of dominance defuzzification is proved to be the overall best performed approach, which is followed by the SAW method with the area center defuzzification. These findings are of practical significance in real-world settings where the selection of the defuzzification-based approaches is required in solving the general fuzzy MADM problems under specific decision contexts.
\end{abstract}

Index Terms-Defuzzification, fuzzy multiattribute decision making (MADM), performance measure, simulation.

\section{INTRODUCTION}

$\mathbf{F}$ UZZY multiattribute decision making (MADM) has been developed for handling the problem of inherent uncertainty and imprecision in human decision-making processes involving multiple attributes [1], [2], [7], [8], [15], [21], [22], [25], [26], [33], [39], [41], [47], [48]. This uncertainty and imprecision may come from various factors such as: 1) incomplete information; 2) abundant information; 3) conflicting evidence; 4) ambiguous information; and 5) subjective information [11], [15], [49], [61], [62]. To effectively tackle this problem, a fuzzy set theory, first proposed by Zadeh [58], has been widely used due to its capability in modeling subjective and imprecise human decision behaviors [20]-[22], [26], [27], [45], [55]-[57], [61], [62].

A fuzzy MADM is concerned with ranking the decision alternatives with respect to multiple, usually conflicting, attributes

Manuscript received January 13, 2005; revised April 16, 2005. This paper was recommended by Associate Editor J. Wu.

H. Deng is with the School of Business Information Technology, RMIT University, Melbourne, Victoria 3001, Australia (e-mail: hepu.deng@ rmit.edu.au).

C.-H. Yeh is with the Faculty of Information Technology, Monash University, Clayton, Victoria 3800, Australia (e-mail: chunghsing.yeh@infotech. monash.edu.au).

Digital Object Identifier 10.1109/TSMCA.2006.878988 and subattributes, if present in a fuzzy environment [5], [11], [14], [15], [37]. It usually involves: 1) determining the fuzzy attribute's weights and the fuzzy ratings of alternatives with respect to each attribute or subattribute and 2) aggregating the fuzzy weights and the fuzzy ratings as an overall fuzzy utility for assessing the overall performance of each alternative across all the attributes and subattributes [10], [11], [14], [15], [31], [37], [47].

Most fuzzy MADM approaches based on multiattribute utility theory [11], [14], [32] require comparing the aggregated fuzzy utilities of alternatives, on which the cardinal ranking of these alternatives can be based [11], [12], [15], [28], [43], [49], [50], [52]. Numerous fuzzy utility comparison approaches have been developed in this regard [5], [9], [10], [13], [18][20], [41], [45], [46], [53]. However, there is no best approach for the general fuzzy MADM problem, and most approaches suffer from various drawbacks such as: 1) lack of sensitivity when comparing similar fuzzy numbers; 2) counterintuitive outcomes in certain circumstances; and 3) complex computational processes [5], [12], [13], [15], [34], [41].

To avoid these drawbacks in fuzzy MADM, defuzzification is widely used as an effective means for aggregating the fuzzy attributes' weights and fuzzy ratings of the alternatives [6], [11], [15], [16], [18], [29], [46], [49], [50]. Numerous defuzzification methods have been developed, and there is no best method. Often, each defuzzification method is used and examined in a specific decision context [12], [15], [16], [49], [58]. However, the relative performance of these methods in solving the general fuzzy MADM problem is not clear. This makes the selection of a specific defuzzification method complex and difficult [6], [42]. To effectively support fuzzy MADM decisions making, a comparative study of these defuzzification methods with respect to their relative performance in ranking decision alternatives is obviously desirable [6], [42].

This paper presents a simulation-based comparative study for evaluating the relative performance of six commonly used defuzzification methods in terms of four new objective performance measures. To generate the ranking outcomes for the comparison, each defuzzification method is used with two most widely used MADM methods: the simple additive weighting (SAW) method [4], [11], [32], [38], [40] and the technique for order preference by similarity to ideal solution (TOPSIS) method [11], [16], [17], [50], [51]. Randomly generated triangular fuzzy numbers are used to represent the decision maker's (DM) fuzzy assessments on the attribute weights and 
the ratings of the alternatives with respect to each attribute. The ranking of the alternatives that resulted from the use of each defuzzification-based approach is compared with each other and also against the efficient fuzzy weighted average (EFWA) approach [12], [18], [30], [46], [53] based on the four new objective performance measures. As a result, 12 defuzzificationbased approaches are examined, and the relative performance of these defuzzification-based approaches in fuzzy MADM is determined.

In the following sections, we first briefly describe six commonly used defuzzification methods that lead to the development of 12 defuzzification-based approaches in fuzzy MADM. We then present the four new objective evaluation measures for evaluating the relative performance of these defuzzificationbased approaches in solving the general fuzzy MADM problem. Finally, we present the simulation results and discuss the observations and their implications derived from the comparative study.

\section{Defuzzification-BASED ApPRoAches}

\section{A. Formulation of the General Fuzzy MADM Problem}

A general fuzzy MADM problem requiring a cardinal ranking usually consists of a finite set of alternatives $A_{i}(i=$ $1,2, \ldots, n)$, which are to be evaluated and ranked based on a given set of attributes $C_{j}(j=1,2, \ldots, m)$ and subattributes $C_{j k}\left(k=1,2, \ldots, p_{j}\right)$, if present. Fuzzy assessments are to be made for determining the ratings of the alternatives and the attribute weights. The ratings $\left(x_{i j}\right.$ or $\left.y_{j k}\right)$ reflect the degree to which the alternative $A_{i}$ satisfies each attribute $C_{j}$ or subattribute $C_{j k}$, which forms the decision matrix $X\left(x_{i j}\right)$ or $Y c_{j}\left(y_{j k}\right)$. The attribute weights $\left(w_{j}\right.$ or $\left.w_{j k}\right)$ represent how important each attribute $C_{j}$ or subattribute $C_{j k}$ is with respect to the overall objective of the problem, which determines the weighting vectors $W=\left(w_{1}, w_{2}, \ldots, w_{m}\right)$ and $W_{j}=\left(w_{j 1}, w_{j 2}, \ldots, w_{j k}\right)$ for the attributes and subattributes, respectively.

A weighted fuzzy performance matrix can be obtained by aggregating the fuzzy decision matrix and the fuzzy weighting vector based on the fuzzy arithmetic operations [11], [31], [62], as

$$
Z=\left[\begin{array}{cccc}
w_{1} x_{11} & w_{2} x_{12} & \ldots & w_{m} x_{1 m} \\
w_{1} x_{21} & w_{2} x_{22} & \ldots & w_{m} x_{2 m} \\
\ldots & \ldots & \ldots & \ldots \\
w_{1} x_{n 1} & w_{2} x_{n 2} & \ldots & w_{m} x_{n m}
\end{array}\right]
$$

If the attribute $C_{j}$ is consists of subattributes $C_{j k}$, the decision vector $\left(x_{1 j}, x_{2 j}, \ldots, x_{n j}\right)$ across all the alternatives with respect to the attributes $C_{j}$ in (1) is first determined by (2). Equation (2) is a normalized value function for the attribute $C_{j}$ with a multilevel hierarchy. The value function is the multiplication of the weighting vector $W_{j}$ for its lower level subattributes $C_{j k}$ and their corresponding decision matrix $Y_{C_{j}}$. It is normalized to make all the vectors of the decision matrix for the attributes at the highest level comparable

$$
\left(x_{1 j}, x_{2 j}, \ldots, x_{n j}\right)=\frac{W_{j} Y_{C_{j}}}{\sum_{k=1}^{p_{j}} w_{j k}} .
$$

Clearly, although the case of a two-level hierarchy is exemplified in this paper, the use of the normalized value function in aggregating the assessments from the lower level subattributes can be applied to the other fuzzy MADM problems involving multilevel attributes.

\section{B. Defuzzification Methods}

In solving fuzzy MADM problems, defuzzification is often applied to the weighted fuzzy performance matrix as given in (1), in order to avoid the complex and unreliable process of comparing the fuzzy utilities [12], [16], [36], [37], [41], [46]. To help present the comparative study, the six most commonly used defuzzification methods are described below, including: 1) right value; 2) degree of optimality; 3) $\alpha$-cut; 4) fuzzy integral; 5) area center; and 6) degree of dominance.

1) Right Value: This method is based on the right portion of a fuzzy number for evaluating the fuzzy decision alternatives [10], [11], [15]. Given the fuzzy vector $\left(w_{j} x_{1 j}\right.$, $\left.w_{j} x_{2 j}, \ldots, w_{j} x_{n j}\right)$ of the weighted fuzzy performance matrix for the attribute $C_{j}$ in (1), a fuzzy maximum $\left(M_{\max }^{j}\right)$ [10], [11], [54] is defined on the real line $R$, to represent the best fuzzy performance rating among all the alternatives with respect to the attribute $C_{j}$ as

$\mu_{M_{\max }^{j}}(x)= \begin{cases}\frac{x-x_{\min }^{j}}{x_{\max }^{j}-x_{\min }^{j}}, & x_{\min }^{j} \leq x \leq x_{\max }^{j}, \quad j=1,2, \ldots, m \\ 0, & \text { otherwise }\end{cases}$

where

$$
\begin{array}{r}
x_{\max }^{j}=\sup \bigcup_{i=1}^{n}\left\{x, x \in R \text { and } 0<\mu_{w_{j} x_{i j}}(x)<1\right\} \\
x_{\min }^{j}=\inf \bigcup_{i=1}^{n}\left\{x, x \in R \text { and } 0<\mu_{w_{j} x_{i j}}(x)<1\right\}, \\
j=1,2, \ldots, m .
\end{array}
$$

The degree to which the alternative $A_{i}$ is the best alternative with respect to the attribute $C_{j}$ can then be calculated by comparing its weighted fuzzy performance $\left(w_{j} x_{i j}\right)$ with the fuzzy maximum $\left(M_{\max }^{j}\right)$, which is given in the following equation:

$r_{i j}=\sup _{x \in R}\left(w_{j} x_{i j} \cap M_{\max }^{j}\right), \quad i=1,2, \ldots, n ; j=1,2, \ldots, m$.

$r_{i j}$ represents the highest degree of approximation of the alternative $A_{i}$ 's weighted performance on the attribute $C_{j}$ to the fuzzy maximum, thus reflecting the DM's optimistic view [50], [54]. This setting is in line with the optimal decision of Bellman and Zadeh [2], who state that "in a fuzzy environment, objectives and constraints formally have the same nature and their confluence can be represented by the intersection of fuzzy sets."

2) Degree of Optimality: The concept of the degree of optimality is based on the comparison of the weighted fuzzy performance $\left(w_{j} x_{i j}\right)$ and the fuzzy maximum $\left(M_{\max }^{j}\right)$ and the fuzzy minimum $\left(M_{\min }^{j}\right)$ for determining the relative performance 
of each alternative $A_{i}$ with respect to each attribute $C_{j}$ [11], [15], [16], [23], [49]. Compared with the right-value defuzzification method, the degree of optimality of the defuzzification method considers not only the right portion of a fuzzy number but also the left portion of the fuzzy number [11], [15], [16], [49]. As a result, all the information characterizing a fuzzy number is used in the defuzzification process.

In this method, a fuzzy minimum $\left(M_{\min }^{j}\right)[10],[11]$ [16], [50] is defined to represent the worst fuzzy performance among all the alternatives with respect to each attribute $C_{j}$, given the weighted fuzzy performance vector $\left(w_{j} x_{1 j}, w_{j} x_{2 j}, \ldots, w_{j} x_{n j}\right)$ for the attribute $C_{j}$, as in (1), by

$$
\mu_{M_{\min }^{j}}(x)= \begin{cases}\frac{x_{\max }^{j}-x}{x_{\max }^{j}-x_{\min }^{j}}, & x_{\min }^{j} \leq x \leq x_{\max }^{j} \\ 0, & \text { otherwise. }\end{cases}
$$

By comparing the weighted fuzzy performance $\left(w_{j} x i j\right)$ of the alternative $A_{i}$ with the fuzzy minimum $\left(M_{\mathrm{min}}^{j}\right)$, the degree to which the alternative $A_{i}$ is not the worst alternative with respect to the attribute $C_{j}$ is calculated as $\left(1-\sup _{x \in R}\left(w_{j} x_{i j} \cap\right.\right.$ $\left.M_{\text {min }}^{j}\right)$ ). As a result, the degree of optimality of the alternative $A_{i}$ with respect to the attribute $C_{j}$ rooted in an alternative where multiple attributes characterize the notion of the best [17], [54], [60] is determined by (7), where $r_{i j}$ indicates the degree of preferability of the alternative $A_{i}$ over all the other alternatives with regard to the attribute $C_{j}$

$$
r_{i j}=\frac{\left.\sup \left(w_{j} x_{i j} \cap M_{\max }^{j}\right)\right)+\left(1-\sup \left(w_{j} x_{i j} \cap M_{\min }^{j}\right)\right)}{2},
$$

3) $\alpha$-Cut: The $\alpha$-cut of a fuzzy set indicates the degree to which an ordinary set belongs to a fuzzy set [9], [16], [45]. By using an $\alpha$-cut on the fuzzy weighted performance matrix in (1), an interval performance matrix can be derived

$$
Z_{\alpha}=\left[\begin{array}{cccc}
{\left[z_{11 l}^{\alpha}, z_{11 r}^{\alpha}\right]} & {\left[z_{12 l}^{\alpha}, z_{12 r}^{\alpha}\right]} & \ldots & {\left[z_{1 m l}^{\alpha}, z_{1 m r}^{\alpha}\right]} \\
{\left[z_{21 l}^{\alpha}, z_{21 r}^{\alpha}\right]} & {\left[z_{22 l}^{\alpha}, z_{22 r}^{\alpha}\right]} & \ldots & {\left[z_{2 m l}^{\alpha}, z_{2 m r}^{\alpha}\right]} \\
\ldots & \ldots & \ldots & \ldots \\
{\left[z_{n 1 l}^{\alpha}, z_{n 1 r}^{\alpha}\right]} & {\left[z_{n 2 l}^{\alpha}, z_{n 2 r}^{\alpha}\right]} & \ldots & {\left[z_{n m l}^{\alpha}, z_{n m r}^{\alpha}\right]}
\end{array}\right]
$$

where $0 \leq \alpha \leq 1$.

An overall crisp performance matrix can be calculated, as

$$
r_{i j \alpha}=\frac{z_{i j r}^{\alpha}+z_{i j l}^{\alpha}}{2}, \quad i=1,2, \ldots, n ; j=1,2, \ldots, m .
$$

4) Fuzzy Integral: A fuzzy integral of a fuzzy number [9], [15] indicates the probability of occurrence for a fuzzy event. Due to its simplicity in concept and in computation for triangular fuzzy numbers, the fuzzy integral of a fuzzy number has been used by Chang [9] and Yager [46] to develop an index for ranking fuzzy numbers.
This method defuzzifies the weighted fuzzy performance matrix in (1) as

$$
r_{i j}=\int_{S_{i j}} x \mu_{w_{j} x_{i j}}(x) d x
$$

where $S_{i j}$ is the support of the fuzzy number $w_{j} x_{i j}(i=$ $1,2, \ldots, n ; j=1,2, \ldots, m)$ in (1).

5) Area Center: The geometric center of a fuzzy number is usually a good representation of a fuzzy number [5], [15], [46]. By using this method, the weighted fuzzy performance matrix is defuzzified by

$$
r_{i j}=\frac{\int_{S_{i j}} x \mu_{w_{j} x_{i j}}(x) d x}{\int_{S_{i j}} \mu_{w_{j} x_{i j}}(x) d x}, \quad i=1,2, \ldots, n ; j=1,2, \ldots, m
$$

where $S_{i j}$ is the support of the fuzzy number $w_{j} x_{i j}$ in (1).

6) Degree of Dominance: The concept of dominance between fuzzy numbers [15], [49] is based on the comparison of fuzzy numbers $A_{i}$ and $A_{j}(i \neq j)$ for determining how much larger or smaller $A_{i}$ is compared to $A_{j}$. Given the weighted fuzzy performance vector $\left(w_{j} x_{1 j}, w_{j} x_{2 j}\right.$, $\ldots, w_{j} x_{n j}$ ) for the attribute $C_{j}$ in (1) and a fuzzy maximum and a fuzzy minimum defined in (2) and (4), the degree to which the fuzzy maximum dominates the weighted fuzzy performance $\left(w_{j} x_{i j}\right)$ of the alternative $A_{i}$ with respect to the attribute $C_{j}$ can be expressed as

$$
\begin{aligned}
d_{i j}^{+} & =d\left(M_{\max }^{j}-w_{j} x_{i j}\right) \\
& =\int D_{\left(M_{\max }^{j}-w_{j} x_{i j}\right)}(\alpha) d \alpha \\
D_{\left(M_{\max }^{j}-w_{j} x_{i j}\right)}(\alpha) & \\
& = \begin{cases}\left.\frac{d^{L \alpha}}{\left(M_{\max }^{j}-w_{j} x_{i j}\right)}\right)^{+d_{\left(M_{\max }-w_{j} x_{i j}\right)}^{R \alpha}}, & 0 \leq \alpha \leq 1 \\
0, & \text { otherwise }\end{cases}
\end{aligned}
$$

where $d_{\left(M_{\max }^{j}-w_{j} x_{i j}\right)}^{L \alpha}$ and $d_{\left(M_{\max }^{j}-w_{j} x_{i j}\right)}^{R \alpha}$ are the lower and upper bounds of the interval, respectively, resulting from the $\alpha$-cut on the difference set $\left(M_{\max }^{j}-w_{j} x_{i j}\right)$.

Similarly, the degree of dominance of the weighted fuzzy performance $\left(w_{j} x_{i j}\right)$ of the alternative $A_{i}$ over the fuzzy minimum $M_{\min }^{j}$ with respect to attribute $C_{j}$ is given as

$$
d_{i j}^{-}=d\left(w_{j} x_{i j}-M_{\min }^{j}\right)=\int D_{\left(w_{j} x_{i j}-M_{\min }^{j}\right)}(\alpha) d \alpha
$$

where

$$
\begin{aligned}
& D_{\left(w_{j} x_{i j}-M_{\min }^{j}\right)}(\alpha) \\
& \quad= \begin{cases}\left.\frac{d^{L \alpha}}{\left(w_{j} x_{i j}-M_{\min }^{j}\right)}\right)_{\left(w_{j} x_{i j}-M_{\min }^{j}\right)}^{R \alpha}, & 0 \leq \alpha \leq 1 \\
0, & \text { otherwise }\end{cases}
\end{aligned}
$$


$d_{\left(w_{j} x_{i j}-M_{\min }^{j}\right)}^{L \alpha}$ and $d_{\left(w_{j} x_{i j}-M_{\min }^{j}\right)}^{R \alpha}$ are the lower and upper bounds of the interval, respectively, resulting from the $\alpha$-cut on the difference set $\left(w_{j} x_{i j}-M_{\min }^{j}\right)$.

Given $d_{i j}^{+}$and $d_{i j}^{-}$, the weighted performance matrix in (1) can be defuzzified by

$$
r_{i j}=\frac{d_{i j}^{-}}{d_{i j}^{+}+d_{i j}^{-}}, \quad i=1,2, \ldots, n ; j=1,2, \ldots, m
$$

where $r_{i j}$ represents the relative performance of the alternative $A_{i}$ with respect to the attribute $C_{j}$.

With the defuzzified performance matrix generated by a defuzzification method, classical MADM methods can be applied to calculate the overall performance index for each alternative across all the attributes. All the alternatives can then be ranked cardinally based on their overall performance index. The next section presents the two most widely used MADM methods, which are to be used in our comparative study.

\section{MADM Methods: SAW and TOPSIS}

The SAW method is probably the most widely accepted and used MADM approaches in real-world settings [4], [11], [28], [32], [38], [43], [47], [59], [60]. This method generates an overall performance index value for each alternative $A_{i}(i=$ $1,2, \ldots, n)$ across all attributes $C_{j}$ by

$$
p_{i}=\frac{\sum_{j=1}^{m} r_{i j} w_{j}}{\sum_{j=1}^{m} w_{j}}, \quad i=1,2, \ldots, n ; j=1,2, \ldots, m
$$

where $r_{i j}$ is the performance rating of alternative $A_{i}$ with respect to attribute $C_{j}$, and $w_{j}$ is the weight of attribute $C_{j}$. The larger the index value is, the higher the ranking of the alternative.

The TOPSIS method is based on the notion that the most preferred alternative should not only have the shortest distance from the positive ideal solution but also have the longest distance from the negative ideal solution [11], [15], [17], [50], [60]. This method has been widely used for solving MADM problems because: 1) its underlying concept is rational and comprehensible and 2) the computation involved is simple.

With the TOPSIS method, the positive and negative ideal solutions [17], [50], [51] can be determined from the defuzzified weighted performed matrix $\left(r_{i j}\right)$ as

$$
\begin{aligned}
A^{+} & =\left(\max _{i}\left(r_{i 1}\right), \max _{i}\left(r_{i 2}\right), \ldots, \max _{i}\left(r_{i m}\right)\right) \\
& =\left(p_{1}^{+}, p_{2}^{+}, \ldots, p_{m}^{+}\right) \\
A^{-} & =\left(\min _{i}\left(r_{i 1}\right), \min _{i}\left(r_{i 2}\right), \ldots, \min _{i}\left(r_{i m}\right)\right) \\
& =\left(p_{1}^{-}, p_{2}^{-}, \ldots, p_{m}^{-}\right) .
\end{aligned}
$$

The weighted Euclidean distances, between each alternative $A_{i}$ and the positive ideal solution $A^{+}$, and between $A_{i}$ and the negative ideal solution $A^{-}$, can be calculated, respectively, as

$$
\begin{aligned}
d_{i}^{+} & =\left[\sum_{j=1}^{m}\left(p_{j}^{+}-r_{i j}\right)^{2}\right]^{1 / 2} \\
d_{i}^{-} & =\left[\sum_{j=1}^{m}\left(r_{i j}-p_{j}^{-}\right)^{2}\right]^{1 / 2}, \quad i=1,2, \ldots, n .
\end{aligned}
$$

The overall performance index value for each alternative across all the attributes can then be determined by

$$
p_{i}=\frac{d_{i}^{-}}{d_{i}^{+}+d_{i}^{-}}, \quad i=1,2, \ldots, n
$$

The larger the index value is, the higher the ranking of the alternative.

\section{Defuzzification-Based Approaches}

A defuzzification-based approach for solving the general fuzzy MADM problem can be developed by combining one of the six defuzzification methods with an MADM method such as SAW or TOPSIS. The procedure for developing such a defuzzification-based approach can be summarized as follows.

Step 1) Obtain the decision matrix for the subattributes, if present.

Step 2) Determine the weighting vectors for the subattributes, if present.

Step 3) Obtain the decision vector for the attributes that have the subattributes.

Step 4) Determine the decision matrix for the attributes by Step 3) or by the DMs assessment on the performance rating of the alternatives regarding each attribute.

Step 5) Determine the weighting vector for the attributes.

Step 6) Obtain the weighted fuzzy performance matrix by multiplying the decision matrix with the weighting vector, as given in (1).

Step 7) Select a specific defuzzification method for defuzzifying the weighted fuzzy performance matrix.

Step 8) Calculate the overall performance index using SAW or TOPSIS.

Step 9) Rank the alternatives in a descending order of their performance index value.

Following the procedure above, 12 defuzzification-based approaches can be developed. Table I lists these approaches and their notation for use in later discussion.

To examine the relative effectiveness and consistency of these defuzzification-based approaches in ranking the decision alternatives, the EFWA approach [12], [18], [19], [30], [45], [53] is selected as a comparison base. This approach is developed based on the concept of the fuzzy weighted average of Dong and Wong [18], [19], [45]. The EFWA approach is further extended by Wang and Liou [53] and applied for 
TABLE I

DEFUZZIFICATION-BASED APPROACHES AND THEIR CORRESPONDING NOTATION

\begin{tabular}{|c|c|c|c|c|}
\hline $\begin{array}{l}\text { No } \\
\text { (b) }\end{array}$ & $\begin{array}{l}\text { Defuzzification } \\
\text { method }\end{array}$ & $\begin{array}{l}\text { MADM } \\
\text { method }\end{array}$ & $\begin{array}{c}\text { Defuzzification-based } \\
\text { approach }\end{array}$ & $\begin{array}{l}\text { Alternative } \\
\text { ranking }\left(g_{i}^{b}\right)\end{array}$ \\
\hline 1 & Right vale $\left(D_{l}\right)$ & SAW & $\mathrm{D}_{1}$-SAW & $g_{i}^{1}$ \\
\hline 2 & Degree of optimality $\left(D_{2}\right)$ & SAW & $\mathrm{D}_{2}$-SAW & $g_{i}^{2}$ \\
\hline 3 & $\alpha$-cut $\left(D_{3}\right)$ & SAW & $\mathrm{D}_{3}$-SAW & $g_{i}^{3}$ \\
\hline 4 & Fuzzy integral $\left(D_{4}\right)$ & SAW & $\mathrm{D}_{4}$-SAW & $g_{i}^{4}$ \\
\hline 5 & Area center $\left(D_{5}\right)$ & SAW & $\mathrm{D}_{5}$-SAW & $g_{i}^{5}$ \\
\hline 6 & Degree of dominance $\left(D_{6}\right)$ & SAW & $\mathrm{D}_{6}$-SAW & $g_{i}^{6}$ \\
\hline 7 & Right vale $\left(D_{l}\right)$ & TOPSIS & $\mathrm{D}_{1}$-TOPSIS & $g_{i}^{7}$ \\
\hline 8 & Degree of optimality $\left(D_{2}\right)$ & TOPSIS & $\mathrm{D}_{2}$-TOPSIS & $g_{i}^{8}$ \\
\hline 9 & $\alpha-\operatorname{cut}\left(D_{3}\right)$ & TOPSIS & $\mathrm{D}_{3}$-TOPSIS & $g_{i}^{9}$ \\
\hline 10 & Fuzzy integral $\left(D_{4}\right)$ & TOPSIS & $\mathrm{D}_{4}$-TOPSIS & $g_{i}^{10}$ \\
\hline 11 & Area center $\left(D_{5}\right)$ & TOPSIS & $\mathrm{D}_{5}$-TOPSIS & $g_{i}^{11}$ \\
\hline 12 & Degree of dominance $\left(D_{6}\right)$ & TOPSIS & $\mathrm{D}_{6}$-TOPSIS & $g_{i}^{12}$ \\
\hline
\end{tabular}

solving a real manufacturing problem by Kao and Liu [30]. The EFWA approach is selected due to: 1) its simplicity in concept and 2) its popularity for solving fuzzy MADM problems [12], [18], [19], [30], [45], [53].

\section{Performance MeAsures}

The performance of the defuzzification-based approaches can be evaluated subjectively or objectively. In a subjective manner, a field study can be conducted using actual cases, and subjective questions are asked in the presence of a selected group of respondents, with respect to the various performance measures such as ease of use, ease of learning, and robustness of the method [4], [6], [24], [38], [43], [59]. The main difficulties in using this approach include: 1) limited sample size and the range of the problem; 2) use of randomly selected respondents rather than real DMs; and 3) existence of biases resulting from learning in the process.

These defuzzification-based approaches can also be evaluated objectively by running a simulation program using randomly generated fuzzy data [4], [6], [12], [24], [34], [38]. This method is widely used as it, when designed properly, can: 1) objectively assess the performance of the approaches and 2) be implemented easily. Considering the nature of this study, the simulation-based evaluation method is more appropriate as the study aims to get an objective view of the relative performance of the 12 defuzzification-based approaches for solving the general fuzzy MADM problem.

To effectively evaluate the simulation result, four new objective performance measures are defined [4], [6], [12], [24], [38], including: 1) ranking accuracy; 2) ranking consistency; 3) ranking correlation; and 4) ranking convergence. These four performance measures are based on five evaluation indexes, including: 1) most favorable alternative index $\left(R_{1}\right) ; 2$ ) ranking equivalence index $\left(R_{2}\right)$; 3) partial ranking consistency index $\left(R_{3}\right)$; 4) mean ranking matches index $\left(R_{4}\right)$; and 5) ranking correlation coefficient index $\left(R_{5}\right)$. The four performance measures and the five evaluation indexes are defined below.

1) Ranking Accuracy: This measure aims to compare the rankings between the EFWA approach and each defuzzification-based approach. It uses the five evaluation indexes to determine the ranking accuracy of the individual defuzzification-based approaches with respect to the EFWA approach. The index of the most favorable alternative $\left(R_{1}\right)$ indicates the percentage of occurrences where the same optimal alternative is derived, which is given as

$$
R_{1}=\frac{\sum_{k=1}^{t} u_{k}}{t}
$$

where $t$ is the number of simulation runs, and $k$ indicates the $k$ th simulation run, and

$$
u_{k}= \begin{cases}1, & g_{i}^{b}=g_{i}^{\mathrm{EFWA}}=1, \quad b=1,2, \ldots, 12 \\ 0, & \text { otherwise. }\end{cases}
$$

In (22) and the following relevant equations, $b$ represents the $b$ th defuzzification-based approach, and $g_{i}^{b}$ and $g_{i}^{\mathrm{EFWA}}$ represent the ranking of the alternative $A_{i}(i=1,2, \ldots, n)$, which resulted from the $b$ th defuzzification-based approach and the EFWA approach, respectively.

The index of ranking equivalence $\left(R_{2}\right)$ represents the percentage of occurrences where an identical ranking of all the alternatives $A_{i}(i=1,2, \ldots, n)$ is generated by a defuzzification-based approach and the EFWA approach, which is calculated by

$$
R_{2}=\frac{\sum_{k=1}^{t} u_{k}}{t}
$$

where

$$
u_{k}= \begin{cases}1, & g_{i}^{b}-g_{i}^{\mathrm{EFWA}}=0, \quad b=1,2, \ldots, 12 \\ 0, & \text { otherwise. }\end{cases}
$$

A partial similar ranking order is achieved when an ordered pair of alternatives in the ranking sequence of one approach matches the ordered pair of the same alternatives in another approach's rankings. The partial consistency index $\left(R_{3}\right)$ shows the percentage of occurrences where a partially similar ranking order is achieved between a defuzzification-based approach and the EFWA approach. This index is calculated by

$$
R_{3}=\frac{\sum_{k=1}^{t} \frac{\sum_{i=1}^{n-1} u_{k}}{n-1}}{t}
$$

where

$$
u_{k}=\left\{\begin{array}{cc}
1, & g_{i}^{b}=g_{i}^{\mathrm{EFWA}} \\
0, & g_{i+1}^{b}=g_{i+1}^{\mathrm{EFWA}} \\
\text { otherwise. }
\end{array}\right.
$$

The index of the mean ranking matches $\left(R_{4}\right)$ reflects the percentage of occurrences where an alternative is ranked in the 
same position between a defuzzification-based approach and the EFWA approach, which is computed by

$$
R_{4}=\sum_{k=1}^{t} \frac{\sum_{i=1}^{n} u_{k}}{n}
$$

where

$$
u_{k}= \begin{cases}1, & g_{i}^{b}=g_{i}^{\mathrm{EFWA}}, \quad b=1,2, \ldots, 12 \\ 0, & \text { otherwise. }\end{cases}
$$

The ranking coefficient index $\left(R_{5}\right)$ is used to determine the relative closeness of the rankings between two defuzzificationbased approaches. This index can be calculated using Spearman's rank order correlation coefficient [3], [34], [35], [44], given as

$$
R_{5}=\frac{\sum_{k=1}^{t}\left\{1-\frac{6 \sum_{i=1}^{n}\left(g_{i}^{d}-g_{i}^{b}\right)^{2}}{n\left(n^{2}-1\right)}\right\}}{t} .
$$

2) Ranking Consistency: The ranking consistency measure aims to scrutinize the consistency of the rankings between any pair of defuzzification-based approaches. It is used to examine the degree of similarity between two defuzzificationbased approaches in ranking decision alternatives. The ranking consistency measure can help identify the defuzzification-based approaches that deviate more from all the other defuzzificationbased approaches and also the approaches that are more likely to produce similar ranking outcomes for specific decision contexts. This information would greatly assist the DMs in selecting the appropriate fuzzy MADM approaches for solving practical problems.

The four indexes defined above $\left(R_{1}-R_{4}\right)$ are used in determining the uniformity among the defuzzification-based approaches. These indexes show the possibility that a defuzzification-based approach produces the same ranking as another approach for a given decision context.

3) Ranking Correlation: The ranking correlation measure aims to analyze the correlation between all the defuzzificationbased approaches in the experiment. The correlation between these approaches is determined using the ranking correlation coefficient $\left(R_{4}\right)$, which is defined in (27). Different from the measure of ranking effectiveness, this measure examines the consistency and accuracy of all the defuzzification-based approaches in ranking the decision alternatives.

4) Ranking Convergence: The ranking convergence measure is used to analyze the performance of individual defuzzification-based approaches against the EFWA approach. The convergence of these defuzzification-based approaches is determined by the ranking correlation coefficient index $\left(R_{5}\right)$. It aims to examine whether a defuzzification-based approach can produce rankings consistent with the EFWA approach.
TABLE II

RANKING ACCURACY OF THE DEFUZZIFICATION-BASED APPROACHES

\begin{tabular}{cllccccc}
\hline $\begin{array}{c}\text { Defuzzification } \\
\text { method }\end{array}$ & $\begin{array}{l}\text { MADM } \\
\text { method }\end{array}$ & $\begin{array}{c}\text { Defuzzification- } \\
\text { based approach }\end{array}$ & $\mathrm{R}_{1}$ & $\mathrm{R}_{2}$ & $\mathrm{R}_{3}$ & $\mathrm{R}_{4}$ & $\mathrm{R}_{5}$ \\
\hline $\mathrm{D}_{1}$ & SAW & $\mathrm{D}_{1}$-SAW & 51.9 & 0.1 & 8.1 & 27.4 & 74.7 \\
$\mathrm{D}_{2}$ & SAW & $\mathrm{D}_{2}$-SAW & 77.5 & 2.1 & 24.3 & 47.7 & 91.2 \\
$\mathrm{D}_{3}$ & SAW & $\mathrm{D}_{3}$-SAW & 64.1 & 0.0 & 13.4 & 35.1 & 83.0 \\
$\mathrm{D}_{4}$ & SAW & $\mathrm{D}_{4}$-SAW & 61.4 & 0.4 & 15.2 & 37.6 & 85.3 \\
$\mathrm{D}_{5}$ & SAW & $\mathrm{D}_{5}$-SAW & 86.2 & 9.1 & 41.6 & 63.0 & 95.9 \\
$\mathrm{D}_{6}$ & SAW & $\mathrm{D}_{6}$-SAW & 86.2 & 9.1 & 41.6 & 63.0 & 95.9 \\
$\mathrm{D}_{1}$ & TOPSIS & D $_{1}$-TOPSIS & 49.4 & 0.2 & 12.7 & 34.3 & 83.6 \\
$\mathrm{D}_{2}$ & TOPSIS & $\mathrm{D}_{2}$-TOPSIS & 75.4 & 2.3 & 26.1 & 49.4 & 91.9 \\
$\mathrm{D}_{3}$ & TOPSIS & $\mathrm{D}_{3}$-TOPSIS & 58.4 & 0.0 & 12.2 & 33.5 & 81.2 \\
$\mathrm{D}_{4}$ & TOPSIS & $\mathrm{D}_{4}$-TOPSIS & 57.8 & 0.2 & 13.4 & 35.6 & 83.9 \\
$\mathrm{D}_{5}$ & TOPSIS & $\mathrm{D}_{5}$-TOPSIS & 82.4 & 6.9 & 37.9 & 60.4 & 95.1 \\
$\mathrm{D}_{6}$ & TOPSIS & $\mathrm{D}_{6}$-TOPSIS & 76.9 & 2.3 & 24.1 & 47.8 & 90.8 \\
\hline
\end{tabular}

\section{Simulation Results AND Discussion}

To evaluate the performance of the 12 defuzzification-based approaches, we conducted a simulation study using a general fuzzy MADM problem characterized by ten decision alternatives and ten attributes, and each attribute had ten subattributes. The simulation study consisted of three phases: 1) running the simulation for producing the performance index values of the decision alternatives and their corresponding rankings; 2) calculating the four objective performance measures in terms of the five indexes; and 3) analyzing these performance measures of the 12 defuzzification-based approaches for examining the relative performance of these approaches.

In the simulation study, the fuzzy assessments on the weights of the attributes and the ratings of the alternatives with respect to each attribute or subattribute were represented with randomly generated triangular fuzzy numbers with values between 1 and 100. To represent all the possible data in the general fuzzy MADM problem, 1000 different datasets were generated by 1000 runs of simulation. For each randomly generated problem dataset in a single run of simulation, the 12 defuzzification-based approaches and the EFWA approach were applied individually to obtain the performance index values of the alternatives and their corresponding rankings. For each approach, these results for the 1000 problem datasets were used to calculate its corresponding values for the four objective performance measures in terms of the five evaluation indexes. The performance index values of the decision alternatives and their corresponding rankings were exported on a text file, on which the statistical package for the social sciences (SPSS) package was applied for calculating the values of the corresponding objective performance measures. The results are summarized in various tables below for further analysis.

Table II shows the ranking accuracy of all the defuzzificationbased approaches. It is clear that no single defuzzificationbased approach can produce the same ranking as the EFWA approach. This is in consistent with the general belief that the selection of a specific defuzzification-based approach for solving a fuzzy MADM problem usually depends on the problem itself, and the performance of a fuzzy MADM approach for a fuzzy MADM problem needs to be examined for an effective decision making in real-world settings [6], [11], [12], [42]. 
TABLE III

RANKING CONSISTENCY OF THE DEFUZZIFICATION-BASED APPROACHES Using the Most Favorable Alternative IndEX

\begin{tabular}{cllcccccc}
\hline $\begin{array}{c}\text { Defuzzification } \\
\text { method }\end{array}$ & MADM & $\begin{array}{c}\text { Defuzzification- } \\
\text { based approach }\end{array}$ & $\mathrm{D}_{1}$ & $\mathrm{D}_{2}$ & $\mathrm{D}_{3}$ & $\mathrm{D}_{4}$ & $\mathrm{D}_{5}$ & $\mathrm{D}_{6}$ \\
\hline $\mathrm{D}_{1}$ & $\mathrm{SAW}$ & $\mathrm{D}_{1}$-SAW & 100.0 & 67.3 & 70.2 & 58.3 & 57.6 & 57.6 \\
$\mathrm{D}_{2}$ & $\mathrm{SAW}$ & $\mathrm{D}_{2}$-SAW & 67.3 & 100.0 & 79.2 & 64.3 & 83.2 & 83.2 \\
$\mathrm{D}_{3}$ & $\mathrm{SAW}$ & $\mathrm{D}_{3}$-SAW & 70.2 & 79.2 & 100.0 & 59.8 & 68.7 & 68.7 \\
$\mathrm{D}_{4}$ & $\mathrm{SAW}$ & $\mathrm{D}_{4}$-SAW & 58.3 & 64.3 & 59.8 & 100.0 & 71.0 & 71.0 \\
$\mathrm{D}_{5}$ & $\mathrm{SAW}$ & $\mathrm{D}_{5}$-SAW & 57.6 & 83.2 & 68.7 & 71.0 & 100.0 & 100.0 \\
$\mathrm{D}_{6}$ & $\mathrm{SAW}$ & $\mathrm{D}_{6}$-SAW & 57.6 & 83.2 & 68.7 & 71.0 & 100.0 & 100.0 \\
$\mathrm{D}_{1}$ & TOPSIS & $\mathrm{D}_{1}$-TOPSIS & 100.0 & 55.7 & 42.2 & 56.6 & 55.3 & 60.5 \\
$\mathrm{D}_{2}$ & TOPSIS & $\mathrm{D}_{2}$-TOPSIS & 55.7 & 100.0 & 67.2 & 60.9 & 77.1 & 81.9 \\
$\mathrm{D}_{3}$ & TOPSIS & $\mathrm{D}_{3}$-TOPSIS & 42.2 & 67.2 & 100.0 & 56.3 & 59.7 & 58.3 \\
$\mathrm{D}_{4}$ & TOPSIS & $\mathrm{D}_{4}$-TOPSIS & 56.6 & 60.9 & 56.3 & 100.0 & 66.2 & 63.8 \\
$\mathrm{D}_{5}$ & TOPSIS & $\mathrm{D}_{5}$-TOPSIS & 55.3 & 77.1 & 59.7 & 66.2 & 100.0 & 79.3 \\
$\mathrm{D}_{6}$ & TOPSIS & $\mathrm{D}_{6}$-TOPSIS & 60.5 & 81.9 & 58.3 & 63.8 & 79.3 & 100.0 \\
\hline
\end{tabular}

TABLE IV

RANKING CONSISTENCY OF THE DEFUZZIFICATION-BASED APPROACHES USING THE RANKING EQUIVALENT INDEX

\begin{tabular}{cllcccccc}
\hline $\begin{array}{c}\text { Defuzzification } \\
\text { method }\end{array}$ & $\begin{array}{c}\text { MADM } \\
\text { method }\end{array}$ & $\begin{array}{c}\text { Defuzzification- } \\
\text { based approach }\end{array}$ & $\mathrm{D}_{1}$ & $\mathrm{D}_{2}$ & $\mathrm{D}_{3}$ & $\mathrm{D}_{4}$ & $\mathrm{D}_{5}$ & $\mathrm{D}_{6}$ \\
\hline $\mathrm{D}_{1}$ & $\mathrm{SAW}$ & $\mathrm{D}_{1}$-SAW & 100 & 0.90 & 1.50 & 0.40 & 0.10 & 0.10 \\
$\mathrm{D}_{2}$ & $\mathrm{SAW}$ & $\mathrm{D}_{2}$-SAW & 0.90 & 100 & 5.09 & 0.80 & 5.99 & 5.99 \\
$\mathrm{D}_{3}$ & $\mathrm{SAW}$ & $\mathrm{D}_{3}$-SAW & 1.50 & 5.09 & 100 & 0.50 & 0.90 & 0.90 \\
$\mathrm{D}_{4}$ & $\mathrm{SAW}$ & $\mathrm{D}_{4}$-SAW & 0.40 & 0.80 & 0.50 & 100 & 2.20 & 2.20 \\
$\mathrm{D}_{5}$ & $\mathrm{SAW}$ & $\mathrm{D}_{5}$-SAW & 0.10 & 5.99 & 0.90 & 2.20 & 100 & 100 \\
$\mathrm{D}_{6}$ & $\mathrm{SAW}$ & $\mathrm{D}_{6}$-SAW & 0.10 & 5.99 & 0.90 & 2.20 & 100 & 100 \\
$\mathrm{D}_{1}$ & TOPSIS & $\mathrm{D}_{1}$-TOPSIS & 100 & 0.50 & 0.20 & 1.20 & 0.50 & 0.30 \\
$\mathrm{D}_{2}$ & TOPSIS & $\mathrm{D}_{2}$-TOPSIS & 0.50 & 100 & 0.70 & 0.20 & 2.70 & 4.30 \\
$\mathrm{D}_{3}$ & TOPSIS & $\mathrm{D}_{3}$-TOPSIS & 0.20 & 0.70 & 100 & 0.10 & 0.00 & 0.20 \\
$\mathrm{D}_{4}$ & TOPSIS & $\mathrm{D}_{4}$-TOPSIS & 1.20 & 0.20 & 0.10 & 100 & 1.20 & 0.90 \\
$\mathrm{D}_{5}$ & TOPSIS & $\mathrm{D}_{5}$-TOPSIS & 0.50 & 2.70 & 0 & 1.20 & 100 & 3.90 \\
$\mathrm{D}_{6}$ & TOPSIS & $\mathrm{D}_{6}$-TOPSIS & 0.30 & 4.30 & 0.20 & 0.90 & 3.90 & 100 \\
\hline
\end{tabular}

Table II also shows that those defuzzification-based approaches using the degree of optimality $\left(D_{2}\right)$, the area center $\left(D_{5}\right)$, and the degree of dominance $\left(D_{6}\right)$ as the method of the defuzzification perform much better than the other defuzzification-based approaches. This may be due to their effective use of all the available information characterizing the fuzzy number in the defuzzification process [16], [47].

To examine the ranking consistency between the defuzzification-based approaches, a pairwise comparison between the 12 approaches is conducted based on the first four indexes $\left(R_{1}-R_{4}\right)$ defined above. Tables III-VI show the results, which are similar to that in Table II.

In Table III, the defuzzification-based approaches based on the degree of optimality $\left(D_{2}\right)$, the area center $\left(D_{5}\right)$, and the degree of dominance $\left(D_{6}\right)$ outperform the others in terms of the most favorable alternative index. This suggests that these three defuzzification methods when combined with SAW and TOPSIS are most likely to produce the same rankings for selecting the most favorable alternative. This may be due to the fact that these three defuzzification methods use similar fuzzy reference sets in their defuzzification process that considers all the information characterizing a fuzzy number [11], [15], [49].

The defuzzification-based approaches associated with the right-value defuzzification method $\left(D_{1}\right)$ have the worst performance in selecting the most favorable alternative, as indicated in Table III. This may be attributed to their use of the infor-
TABLE V

RANKING CONSISTENCY OF THE DEFUZZIFICATION-BASEd APPROACHES USING THE PARTIAL CONSISTENCY INDEX

\begin{tabular}{cllcccccc}
\hline $\begin{array}{c}\text { Defuzzification } \\
\text { method }\end{array}$ & $\begin{array}{l}\text { MADM } \\
\text { method }\end{array}$ & $\begin{array}{c}\text { Defuzzification- } \\
\text { based approach }\end{array}$ & $\mathrm{D}_{1}$ & $\mathrm{D}_{2}$ & $\mathrm{D}_{3}$ & $\mathrm{D}_{4}$ & $\mathrm{D}_{5}$ & $\mathrm{D}_{6}$ \\
\hline $\mathrm{D}_{1}$ & SAW & $\mathrm{D}_{1}$-SAW & 100.0 & 18.06 & 22.19 & 10.89 & 10.82 & 10.82 \\
$\mathrm{D}_{2}$ & $\mathrm{SAW}$ & $\mathrm{D}_{2}$-SAW & 18.06 & 100.0 & 32.30 & 15.76 & 33.62 & 33.62 \\
$\mathrm{D}_{3}$ & $\mathrm{SAW}$ & $\mathrm{D}_{3}$-SAW & 22.19 & 32.30 & 100.0 & 11.52 & 16.95 & 16.95 \\
$\mathrm{D}_{4}$ & $\mathrm{SAW}$ & $\mathrm{D}_{4}$-SAW & 10.89 & 15.76 & 11.52 & 100.0 & 25.58 & 25.58 \\
$\mathrm{D}_{5}$ & $\mathrm{SAW}$ & $\mathrm{D}_{5}$-SAW & 10.82 & 33.62 & 16.95 & 25.58 & 100.0 & 100.0 \\
$\mathrm{D}_{6}$ & $\mathrm{SAW}$ & $\mathrm{D}_{6}$-SAW & 10.82 & 33.62 & 16.95 & 25.58 & 100.0 & 100.0 \\
$\mathrm{D}_{1}$ & TOPSIS & $\mathrm{D}_{1}$-TOPSIS & 100.0 & 17.68 & 11.61 & 18.06 & 15.55 & 15.94 \\
$\mathrm{D}_{2}$ & TOPSIS & $\mathrm{D}_{2}$-TOPSIS & 17.68 & 100.0 & 16.95 & 12.01 & 27.24 & 30.98 \\
$\mathrm{D}_{3}$ & TOPSIS & $\mathrm{D}_{3}$-TOPSIS & 11.61 & 16.95 & 100.0 & 8.95 & 10.39 & 9.59 \\
$\mathrm{D}_{4}$ & TOPSIS & $\mathrm{D}_{4}$-TOPSIS & 18.06 & 12.01 & 8.95 & 100.0 & 20.19 & 17.43 \\
$\mathrm{D}_{5}$ & TOPSIS & D $_{5}$-TOPSIS & 15.55 & 27.24 & 10.39 & 20.19 & 100.0 & 30.16 \\
$\mathrm{D}_{6}$ & TOPSIS & D $_{6}$-TOPSIS & 15.94 & 30.98 & 9.59 & 17.43 & 30.16 & 100.0 \\
\hline
\end{tabular}

TABLE VI

RANKING CONSISTENCY OF THE DEFUZZIFICATION-BASEd APPROACHES Using THE MEAN RANKING Matches InDEX

\begin{tabular}{cllllllll}
\hline $\begin{array}{c}\text { Defuzzification } \\
\text { method }\end{array}$ & $\begin{array}{l}\text { MADM } \\
\text { method }\end{array}$ & $\begin{array}{c}\text { Defuzzification- } \\
\text { based approach }\end{array}$ & $\mathrm{D}_{1}$ & $\mathrm{D}_{2}$ & $\mathrm{D}_{3}$ & $\mathrm{D}_{4}$ & $\mathrm{D}_{5}$ & $\mathrm{D}_{6}$ \\
\hline $\mathrm{D}_{1}$ & $\mathrm{SAW}$ & $\mathrm{D}_{1}$-SAW & 100.0 & 39.89 & 45.08 & 30.96 & 31.25 & 31.25 \\
$\mathrm{D}_{2}$ & $\mathrm{SAW}$ & $\mathrm{D}_{2}$-SAW & 39.89 & 100.0 & 54.69 & 38.46 & 57.02 & 57.02 \\
$\mathrm{D}_{3}$ & $\mathrm{SAW}$ & $\mathrm{D}_{3}$-SAW & 45.08 & 54.69 & 100.0 & 32.44 & 39.44 & 39.44 \\
$\mathrm{D}_{4}$ & $\mathrm{SAW}$ & $\mathrm{D}_{4}$-SAW & 30.96 & 38.46 & 32.44 & 100.0 & 48.78 & 48.78 \\
$\mathrm{D}_{5}$ & $\mathrm{SAW}$ & $\mathrm{D}_{5}$-SAW & 31.25 & 57.02 & 39.44 & 48.78 & 100.0 & 31.25 \\
$\mathrm{D}_{6}$ & SAW & $\mathrm{D}_{6}$-SAW & 31.25 & 57.02 & 39.44 & 48.78 & 31.25 & 100.0 \\
$\mathrm{D}_{1}$ & TOPSIS & $\mathrm{D}_{1}$-TOPSIS & 100.0 & 40.91 & 32.66 & 40.26 & 37.82 & 38.39 \\
$\mathrm{D}_{2}$ & TOPSIS & $\mathrm{D}_{2}$-TOPSIS & 40.91 & 100.0 & 39.31 & 33.94 & 50.38 & 54.11 \\
$\mathrm{D}_{3}$ & TOPSIS & $\mathrm{D}_{3}$-TOPSIS & 32.66 & 39.31 & 100.0 & 28.87 & 31.20 & 29.25 \\
$\mathrm{D}_{4}$ & TOPSIS & $\mathrm{D}_{4}$-TOPSIS & 40.26 & 33.94 & 28.87 & 100.0 & 43.61 & 53.38 \\
$\mathrm{D}_{5}$ & TOPSIS & $\mathrm{D}_{5}$-TOPSIS & 37.82 & 50.38 & 31.20 & 43.61 & 100.0 & 38.39 \\
$\mathrm{D}_{6}$ & TOPSIS & $\mathrm{D}_{6}$-TOPSIS & 38.39 & 54.11 & 29.25 & 53.38 & 38.39 & 100.0 \\
\hline
\end{tabular}

mation only on the right portion of a fuzzy number and their ignorance of the information on the left portion of the fuzzy number in the defuzzification process [10], [12], [15], [49].

An interesting phenomenon that can be observed from Table III is that the $D_{5}$-SAW and $D_{6}$-SAW approaches generate the same result for the most favorable alternative index. This suggests that the defuzzification methods of the area center $\left(D_{5}\right)$ and the degrees of dominance $\left(D_{6}\right)$ when used with the SAW produce an identical ranking for the most favorable alternative at every single simulation run for a given decision setting. In practical terms, this means that it makes no difference as to which of these two approaches to choose if a DM is only concerned about selecting the best decision alternative in a given situation.

Table IV shows a very low index value with respect to the ranking equivalent index between the defuzzification-based approaches, with the exception of those approaches based on the area center $\left(D_{5}\right)$ and the degree of dominance $\left(D_{6}\right)$ associated with SAW. This suggests that these defuzzificationbased approaches, other than $D_{5}$-SAW and $D_{6}$-SAW, are highly unlikely to produce the same ranking for the same decision setting. It also shows that the use of a specific defuzzification method for developing a defuzzification-based fuzzy MADM approach does have a significant effect on the final ranking outcomes of the decision alternatives in a given decision setting. 
TABLE VII

RANKING CORRELATION OF THE DEFUZZIFICATION-BASED APPROACHES

\begin{tabular}{cllcccccc}
\hline $\begin{array}{c}\text { Defuzzification } \\
\text { method }\end{array}$ & MADM & Defuzzification- & $\mathrm{D}_{1}$ & $\mathrm{D}_{2}$ & $\mathrm{D}_{3}$ & $\mathrm{D}_{4}$ & $\mathrm{D}_{5}$ & $\mathrm{D}_{6}$ \\
\hline $\mathrm{D}_{1}$ & SAW & $\mathrm{D}_{1}$-SAW & 100.0 & 87.2 & 90.2 & 78.4 & 79.5 & 79.5 \\
$\mathrm{D}_{2}$ & SAW & $\mathrm{D}_{2}$-SAW & 87.2 & 100.0 & 93.4 & 85.7 & 94.0 & 94.0 \\
$\mathrm{D}_{3}$ & SAW & $\mathrm{D}_{3}$-SAW & 90.2 & 93.4 & 100.0 & 80.1 & 85.6 & 85.6 \\
$\mathrm{D}_{4}$ & SAW & $\mathrm{D}_{4}$-SAW & 78.4 & 85.7 & 80.1 & 100.0 & 91.2 & 79.5 \\
$\mathrm{D}_{5}$ & SAW & $\mathrm{D}_{5}$-SAW & 79.5 & 94.0 & 85.6 & 91.2 & 100.0 & 100.0 \\
$\mathrm{D}_{6}$ & SAW & $\mathrm{D}_{6}$-SAW & 79.5 & 94.0 & 85.6 & 79.5 & 100.0 & 100.0 \\
$\mathrm{D}_{1}$ & TOPSIS & $\mathrm{D}_{1}$-TOPSIS & 100.0 & 87.6 & 78.6 & 87.9 & 86.4 & 86.2 \\
$\mathrm{D}_{2}$ & TOPSIS & $\mathrm{D}_{2}$-TOPSIS & 87.6 & 100.0 & 85.5 & 82.8 & 92.2 & 92.8 \\
$\mathrm{D}_{3}$ & TOPSIS & $\mathrm{D}_{3}$-TOPSIS & 78.6 & 85.5 & 100.0 & 75.0 & 79.2 & 75.7 \\
$\mathrm{D}_{4}$ & TOPSIS & $\mathrm{D}_{4}$-TOPSIS & 87.9 & 82.8 & 75.0 & 100.0 & 88.6 & 86.4 \\
$\mathrm{D}_{5}$ & TOPSIS & $\mathrm{D}_{5}$-TOPSIS & 86.4 & 9.2 & 79.2 & 88.6 & 100.0 & 93.0 \\
$\mathrm{D}_{6}$ & TOPSIS & $\mathrm{D}_{6}$-TOPSIS & 86.2 & 92.8 & 75.7 & 86.4 & 93.0 & 100.0 \\
\hline
\end{tabular}

Table V shows that the 12 defuzzification-based approaches have a similar performance about the partial consistency index, as compared to the ranking equivalent index. Again, when used with SAW, both the area center $\left(D_{5}\right)$ and the degree of dominance $\left(D_{6}\right)$ methods of the defuzzification produce the same rankings.

It is evident from Tables III-VI that those defuzzificationbased approaches using the area center $\left(D_{5}\right)$ and the degree of dominance $\left(D_{6}\right)$ for defuzzification produce the highest values consistently across all the evaluation indexes, which is followed by those approaches with the degree of optimality $\left(D_{2}\right)$ method. The approaches using the fuzzy integral $\left(D_{4}\right)$ method are the worst performer among all the defuzzificationbased approaches. This again may be because the defuzzification methods of the degree of optimality $\left(D_{2}\right)$, the area center $\left(D_{5}\right)$, and the degree of dominance $\left(D_{6}\right)$ use all the information effectively on both the left and right sides of a fuzzy number in the defuzzification process [10], [11], [16], [49].

It can also be noted in Tables III-VI that SAW produces a more consistent ranking outcome than TOPSIS, regardless of the defuzzification method applied. This suggests that SAW is a better choice for developing the defuzzification-based approaches in solving the general fuzzy MADM problem due to: 1) soundness of the underlying utility theory [11], [31] and 2) linearity of the mathematical formulation [4], [32].

Table VII gives the average ranking correlation coefficient between the 12 defuzzification-based approaches. It shows that the approaches using the $\alpha$-cut $\left(D_{3}\right)$ and the fuzzy integral $\left(D_{4}\right)$ for defuzzification are least correlated. It also demonstrates that the approaches using the fuzzy integral $\left(D_{4}\right)$ and the right value $\left(D_{1}\right)$ for defuzzification are perfectly correlated. This means that the defuzzification-based approaches using the $\alpha$-cut $\left(D_{3}\right)$ and the fuzzy integral $\left(D_{4}\right)$ for defuzzification are least likely to produce similar rankings in a given situation. The approaches that are based on the fuzzy integral $\left(D_{4}\right)$ and the right value $\left(D_{1}\right)$ for defuzzification always produce the same rankings for the same fuzzy MADM problem.

Table VII shows that a $100 \%$ ranking correlation is achieved between the approach using the area center method $\left(D_{5}\right)$ and the approach using the degree of dominance method $\left(D_{6}\right)$
TABLE VIII

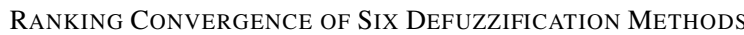
WITH RESPECT TO SAW AND TOPSIS AND THEIR Relative PERFormance

\begin{tabular}{ccccc}
\hline $\begin{array}{c}\text { Defuzzification } \\
\text { method }\end{array}$ & SAW & $\begin{array}{c}\text { Performance } \\
\text { ranking }\end{array}$ & TOPSIS & $\begin{array}{c}\text { Performance } \\
\text { ranking }\end{array}$ \\
\hline $\mathrm{D}_{1}$ & 74.72 & 6 & 83.64 & 5 \\
$\mathrm{D}_{2}$ & 91.25 & 3 & 91.92 & 2 \\
$\mathrm{D}_{3}$ & 83.00 & 5 & 81.22 & 6 \\
$\mathrm{D}_{4}$ & 85.35 & 4 & 83.87 & 4 \\
$\mathrm{D}_{5}$ & 95.88 & 1 & 95.10 & 1 \\
$\mathrm{D}_{6}$ & 95.88 & 1 & 87.76 & 3 \\
\hline
\end{tabular}

TABLE IX

Performance Ranking of the DefuZZiFICATION-BASED APPROACHES With Respect to the Four Objective Performance Measures

\begin{tabular}{l|c|c|c|c|c}
\hline $\begin{array}{l}\text { Defuzzification- } \\
\text { based approach }\end{array}$ & $\begin{array}{c}\text { Ranking } \\
\text { accuracy }\end{array}$ & $\begin{array}{c}\text { Ranking } \\
\text { consistency }\end{array}$ & $\begin{array}{c}\text { Ranking } \\
\text { correlation }\end{array}$ & $\begin{array}{c}\text { Ranking } \\
\text { convergence }\end{array}$ & $\begin{array}{c}\text { Overall } \\
\text { performance }\end{array}$ \\
\hline $\mathrm{D}_{1}$-SAW & 11 & 9 & 10 & 12 & 11 \\
$\mathrm{D}_{2}$-SAW & 4 & 3 & 1 & 5 & 3 \\
$\mathrm{D}_{3}$-SAW & 7 & 4 & 4 & 10 & 6 \\
$\mathrm{D}_{4}$-SAW & 8 & 8 & 9 & 7 & 8 \\
$\mathrm{D}_{5}$-SAW & 1 & 1 & 3 & 1 & 2 \\
$\mathrm{D}_{6}$-SAW & 1 & 1 & 2 & 1 & 1 \\
$\mathrm{D}_{1}$-TOPSIS & 12 & 12 & 7 & 9 & 10 \\
$\mathrm{D}_{2}$-TOPSIS & 6 & 6 & 5 & 4 & 4 \\
$\mathrm{D}_{3}$-TOPSIS & 9 & 11 & 11 & 11 & 11 \\
$\mathrm{D}_{4}$-TOPSIS & 10 & 10 & 8 & 8 & 9 \\
D5 $_{5}$-TOPSIS & 3 & 7 & 12 & 3 & 6 \\
D $_{6}$-TOPSIS & 5 & 5 & 6 & 6 & 5 \\
\hline
\end{tabular}

associated with the SAW. With a reasonable confidence, these two defuzzification-based approaches would produce the same ranking for the general fuzzy MADM problem.

The ranking convergence of the defuzzification-based approaches is determined by comparing the overall rankings of a defuzzification-based approach with that of the EFWA approach, which is based on the Spearman's correlation coefficient [45]. Table VIII shows the result.

Table VIII shows that the approaches based on the degree of optimality $\left(D_{2}\right)$ method, the area center $\left(D_{5}\right)$ method, and the degree of dominance method $\left(D_{6}\right)$ produce more consistent rankings than those approaches based on other defuzzification methods. This reinforces the previous finding that the effective use of all the available information for defuzzifying fuzzy numbers is critical in developing effective fuzzy MADM approaches [11], [15], [49]. This reinforced finding suggests that the approaches based on a defuzzification method capable of using all the available information of the fuzzy numbers are more effective in solving the general fuzzy MADM problem [11], [48].

To provide an effective aid to the DMs for selecting the appropriate defuzzification-based approaches in solving the fuzzy MADM problems, Table IX summarizes the relative performance of the 12 defuzzification-based approaches with respect to the four objective performance measures. The overall 
TABLE $\mathrm{X}$

Performance Ranking of the DefuZZification-BASEd APProaches Under Two SPECIFIC DeCision SETTINGS

\begin{tabular}{lcc}
\hline Defuzzification-based approach & Selecting the best alternative & Ranking all alternatives \\
\hline $\mathrm{D}_{1}$-SAW & 11 & 12 \\
$\mathrm{D}_{2}$-SAW & 4 & 5 \\
$\mathrm{D}_{3}$-SAW & 7 & 10 \\
$\mathrm{D}_{4}$-SAW & 8 & 7 \\
$\mathrm{D}_{5}$-SAW & 1 & 1 \\
$\mathrm{D}_{6}$-SAW & 1 & 1 \\
$\mathrm{D}_{5}$-TOPSIS & 12 & 9 \\
$\mathrm{D}_{2}$-TOPSIS & 6 & 4 \\
$\mathrm{D}_{3}$-TOPSIS & 9 & 11 \\
$\mathrm{D}_{4}$-TOPSIS & 10 & 8 \\
D $_{5}$-TOPSIS & 3 & 3 \\
$\mathrm{D}_{6}$-TOPSIS & 5 & 6 \\
\hline
\end{tabular}

performance of the individual approaches is determined based on the aggregated scores of the rankings with respect to each criterion.

Table IX shows that $D_{6}$-SAW is the best defuzzificationbased approach for solving the general fuzzy MADM problem, which is followed by $D_{5}$-SAW, $D_{2}$-SAW, and $D_{2}$-TOPSIS, across all the objective performance measures. This phenomenon reinforces our notion that an effective defuzzificationbased approach has to use all the available information of a fuzzy number in the defuzzification process [10], [11], [15], [49].

It is also evident in Table IX that those defuzzificationbased approaches based on SAW outperform those approaches associated with TOPSIS. This suggests that SAW is a preferred choice for developing the defuzzification-based approaches in fuzzy MADM.

Two common decision settings in fuzzy MADM often present in real situations are: 1) selecting the best alternative from a given set of alternatives and 2) ranking all the decision alternatives. Depending on the decision setting involved, different defuzzification-based approaches can be selected for effective decision making. Table $\mathrm{X}$ presents an overall ranking of these defuzzification-based approaches with respect to these two decision settings.

Based on the research findings above, a real expert system can be developed, which can facilitate the selection of the specific defuzzification-based approaches with respect to the circumstance of a specific decision situation such as the decision-making settings 1) or 2) [11]. Linguistic rules [11], [15], [50], [51] can be developed to adequately capture the DM's requirements and the characteristics of the decision situation. As a result, effective decision aids can be provided. More research is required to adequately address this issue.

\section{CONCLUSION}

This paper has presented an objective comparative study based on simulation in order to examine the performance of
12 defuzzification-based approaches for solving the general fuzzy MADM problem. Some specific performance measures and decision settings are identified, and the effectiveness and consistency of these approaches are highlighted. The fuzzy MADM approaches based on SAW and defuzzification methods of using all the available information of the fuzzy numbers would produce effective and consistent rankings. The findings in this paper provide valuable insights for selecting the appropriate defuzzification methods in actual decision settings.

\section{REFERENCES}

[1] B. S. Ahn, "Extending Malakooti's model for ranking multicriteria alternatives with preference strength and partial information," IEEE Trans. Syst., Man, Cybern., vol. 33, no. 3, pp. 281-287, May 2003.

[2] R. E. Bellman and L. A. Zadeh, "Decision making in a fuzzy environment," Manage. Sci., vol. 17, no. 4, pp. 141-164, 1970.

[3] M. L. Berenson and D. M. Levine, Basic Business Statistics: Concepts and Applications. Englewood Cliffs, NJ: Prentice-Hall, 1992.

[4] M. Beuthe and G. Scannella, "Comparative analysis of UTA multicriteria methods," Eur. J. Oper. Res., vol. 130, no. 2, pp. 246-262, Apr. 2001.

[5] G. Bortolan and P. Degani, "A review of some methods for ranking fuzzy subsets," Fuzzy Sets Syst., vol. 15, no. 1, pp. 1-19, Feb. 1985.

[6] T. O. Boucher and O. Gogus, "Reliability, validity, and imprecision in fuzzy multicriteria decision-making," IEEE Trans. Syst., Man, Cybern., vol. 32, no. 3, pp. 190-202, Aug. 2002.

[7] C. Carlsson, "Tackling an MCDM-problem with the help of some results from fuzzy set theory," Eur. J. Oper. Res., vol. 10, no. 3, pp. 270-281, Jul. 1982.

[8] C. Carlsson and R. Fuller, "Fuzzy multiple attributes decision making: Recent developments," Fuzzy Sets Syst., vol. 78, no. 2, pp. 139-153, Mar. 1996.

[9] W. Chang, "Ranking of fuzzy utilities with triangular membership functions," in Proc. Int. Conf. Policy Anal. Syst., 1981, pp. 263-272.

[10] S. H. Chen, "Ranking fuzzy numbers with maximising and minimising set," Fuzzy Sets Syst., vol. 17, no. 2, pp. 113-129, Nov. 1985.

[11] S. J. Chen and C. L. Hwang, Fuzzy Multiple Attribute Decision Making: Methods and Applications. New York: Springer-Verlag, 1992.

[12] C. Chen and C. M. Klein, "An efficient method to solving fuzzy MADM problems," Fuzzy Sets Syst., vol. 88, no. 1, pp. 51-67, May 1997.

[13] F. Choobineh and H. Li, "An index for ordering fuzzy numbers," Fuzzy Sets Syst., vol. 54, no. 3, pp. 287-294, Mar. 1993.

[14] J. J. Cristiano, C. C. White, and J. K. Liker, "Application of multiattribute decision analysis to quality function deployment for target setting," IEEE Trans. Syst., Man, Cybern., vol. 31, no. 3, pp. 366-382, Aug. 2001.

[15] H. Deng, "Developments in fuzzy multiattributes analysis and their applications to decision problems," Ph.D. thesis, Monash Univ., Clayton, Australia, 1999.

[16] — - "Multiattributes analysis with fuzzy pairwise comparison," Int. J. Approx. Reason., vol. 21, no. 3, pp. 215-231, 1999.

[17] H. Deng, C.-H. Yeh, and R. J. Willis, "Inter-company comparison using modified TOPSIS with objective weights," Comput. Oper. Res., vol. 27, no. 10 , pp. 963-973, Sep. 2000.

[18] H. L. Dong and D. Park, "An efficient algorithm for fuzzy weighted average," Fuzzy Sets Syst., vol. 87, no. 1, pp. 39-45, Apr. 1996.

[19] W. M. Dong and F. S. Wong, "Fuzzy weighted average and implementation of the extension principle," Fuzzy Sets Syst., vol. 21, no. 2, pp. 183199, Feb. 1986.

[20] D. Dubois and H. Prade, "A unifying view of comparison indices in a fuzzy set-theoretic framework," in Fuzzy Set and Possibility Theory-Recent Development, R. R. Yager, Ed. New York: Pergamon, 1982, pp. 3-13.

[21] — "Fuzzy sets-A convenient fiction for modeling vagueness and possibility," IEEE Trans. Fuzzy Syst., vol. 2, no. 1, pp. 16-21, Feb. 1994.

[22] J. Efstathiou and V. Rajkovic, "Multiattribute decision making using a fuzzy heuristic approach," IEEE Trans. Syst., Man, Cybern., vol. SMC-9, no. 6, pp. 326-333, Jun. 1979.

[23] M. Farina and P. Amato, "A fuzzy definition of 'optimality' for manycriteria optimization problems," IEEE Trans. Syst., Man, Cybern., vol. 34, no. 3, pp. 315-326, May 2004.

[24] M. A. Gil, M. Lopez-Diaz, and L. J. Rodriguez-Muniz, "An improvement of a comparison of experiments in statistical decision problems with fuzzy utilities," IEEE Trans. Syst., Man, Cybern., vol. 28, no. 6, pp. 856-864, Nov. 1998. 
[25] H. Hellendoorn, "After the fuzzy wave reached Europe," Eur. J. Oper. Res., vol. 99, no. 1, pp. 58-71, May 1997.

[26] F. Herrera and J. L. Verdegay, "Fuzzy sets and operations research: Perspectives," Fuzzy Sets Syst., vol. 90, no. 2, pp. 207-218, Sep. 1997.

[27] E. Herrera-Viedma, F. Herrera, and F. Chiclana, "A consensus model for multiperson decision making with different preference structures," IEEE Trans. Syst., Man, Cybern., vol. 32, no. 3, pp. 394-402, May 2002.

[28] J.-S. R. Jang, C.-T. Sun, and E. Mizutani, Neuro-Fuzzy and Soft Computing. Englewood Cliffs, NJ: Prentice-Hall, 1997.

[29] T. Jiang and Y. Li, "Generalized defuzzification strategies and their parameter learning procedures," IEEE Trans. Fuzzy Syst., vol. 4, no. 1, pp. 64-71, Feb. 1996.

[30] C. Kao and S. T. Liu, "Competitiveness of manufacturing firms: An application of fuzzy weighted average," IEEE Trans. Syst., Man, Cybern., vol. 29, no. 6, pp. 661-667, Nov. 1999.

[31] A. Kaufmann and M. M. Gupta, Introduction to Fuzzy Arithmetic Theory and Application. New York: Van Nostrand Reinhold, 1985.

[32] R. L. Keeney and H. Raiffa, Decisions With Multiple Objectives: Preference and Value Tradeoffs. Cambridge, U.K.: Cambridge Univ. Press, 1993.

[33] R. C. Kwok, J. Ma, and D. Zhou, "Improving group decision making: A fuzzy GSS approach," IEEE Trans. Syst., Man, Cybern., vol. 32, no. 1, pp. 54-63, Feb. 2002.

[34] M. Ma, A. Kandel, and M. Friedman, "Representing and comparing two kinds of fuzzy numbers," IEEE Trans. Syst., Man, Cybern., vol. 28, no. 4, pp. 573-576, Nov. 1998.

[35] S. Makridakis, S. C. Wheelwright, and V. E. McGee, Forecasting: Methods and Applications. New York: Wiley, 1983.

[36] B. Malakooti, "Ranking and screening multiple criteria alternatives with partial information and use of ordinal and cardinal strength of preferences," IEEE Trans. Syst., Man, Cybern., vol. 30, no. 3, pp. 355-368, May 2000.

[37] L. Mikhailov and M. G. Singh, "Fuzzy analytic network process and its application to the development of decision support systems," IEEE Trans. Syst., Man, Cybern., vol. 33, no. 1, pp. 33-41, Feb. 2003.

[38] D. L. Olson, "Comparison of three multicriteria methods to predict known outcomes," Eur. J. Oper. Res., vol. 130, no. 3, pp. 576-587, May 2001.

[39] K. S. Park, "Mathematical programming models for characterizing dominance and potential optimality when multicriteria alternative values and weights are simultaneously incomplete," IEEE Trans. Syst., Man, Cybern., vol. 34, no. 5, pp. 601-614, Sep. 2004.

[40] R. Ramanathan, "A multicriteria methodology for global negotiations on climate change," IEEE Trans. Syst., Man, Cybern., vol. 28, no. 4, pp. 541548, Nov. 1998

[41] R. A. Ribeiro, "Fuzzy multiple attribute decision making: A review and new preference elicitation techniques," Fuzzy Sets Syst., vol. 78, no. 2, pp. 155-181, Mar. 1996.

[42] T. A. Runkler, "Selection of appropriate defuzzification methods using application specific properties," IEEE Trans. Fuzzy Syst., vol. 5, no. 1, pp. 72-79, Feb. 1997.

[43] A. A. Salo and R. P. Hamalainen, "Preference ratios in multiattribute evaluation (PRIME)-Elicitation and decision procedures under incomplete information," IEEE Trans. Syst., Man, Cybern., vol. 31, no. 6, pp. 533545, Nov. 2001.

[44] C. E. Spearman, The Abilities of Man: Their Nature and Measurements. New York: AMS Press, 1930.

[45] R. R. Yager, "On ordered weighted averaging aggregation operators in multicriteria decision making," IEEE Trans. Syst., Man, Cybern., vol. 18, no. 1, pp. 183-190, Jan./Feb. 1988

[46] _ _ "Ranking fuzzy subsets over the unit interval," in Proc. CDC, 1978, pp. 1435-14437.

[47] J.-B. Yang and D.-L. Xu, "On the evidential reasoning algorithm for multiple attribute decision analysis under uncertainty," IEEE Trans. Syst., Man, Cybern., vol. 32, no. 3, pp. 289-304, May 2002.

[48] _ "Nonlinear information aggregation via evidential reasoning in multiattribute decision analysis under uncertainty," IEEE Trans. Syst., Man, Cybern., vol. 32, no. 3, pp. 376-393, May 1998.

[49] C.-H. Yeh and H. Deng, "A practical approach to fuzzy utilities comparison in fuzzy multicriteria analysis," Int. J. Approx. Reason., vol. 35, no. 2, pp. 179-194, Feb. 2004.

[50] C.-H. Yeh, H. Deng, and Y.-H. Chang, "Fuzzy multicriteria analysis for performance evaluation of bus companies," Eur. J. Oper. Res., vol. 126, no. 3, pp. 459-473, Nov. 2000.

[51] C.-H. Yeh, R. J. Willis, H. Deng, and H. Pan, "Task oriented weighting in multi-criteria analysis," Eur. J. Oper. Res., vol. 119, no. 1, pp. 130-146, Nov. 1999.
[52] L. Wang and Y. Frayman, "A dynamically generated fuzzy neural network and its application to torsional vibration control of tandem cold rolling mill spindles," Eng. Appl. Artif. Intell., vol. 15, no. 6, pp. 541-550, Dec. 2002.

[53] M. J. Wang and T. L. Liou, "Fuzzy weighted average: An improved algorithm," Fuzzy Sets Syst., vol. 49, no. 3, pp. 307-315, Aug. 1992.

[54] L. A. Zadeh, "Maximizing sets and fuzzy Markoff algorithms," IEEE Trans. Syst., Man, Cybern., vol. 28, no. 1, pp. 9-15, Feb. 1998.

[55] — - "The concept of a linguistic variable and its application to approximate reasoning: I," Inf. Sci., vol. 8, no. 3, pp. 199-249, 1975.

[56] _ - "The concept of a linguistic variable and its application to approximate reasoning: II," Inf. Sci., vol. 8, no. 4, pp. 301-357, 1975.

[57] _ "Outline of a new approach to the analysis of complex system and decision process," IEEE Trans. Syst., Man, Cybern., vol. SMC-3, no. 1, pp. 28-44, 1973.

[58] —_ "Fuzzy sets," Inf. Cont., vol. 8, no. 3, pp. 338-353, Jun. 1965.

[59] S. H. Zanakis, A. Solomon, N. Wishart, and S. Dublish, "Multi-attribute decision making: A simulation comparison of select methods," Eur. J. Oper. Res., vol. 107, no. 3, pp. 507-529, Jun. 1998.

[60] M. Zeleny, "Multiple attributes decision making: Eight concepts of optimality," Human Syst. Manage., vol. 17, no. 2, pp. 97-107, 1998.

[61] H.-J. Zimmermann, "An application-oriented view of modeling uncertainty," Eur. J. Oper. Res., vol. 122, no. 2, pp. 190-198, Apr. 2000.

[62] — - Fuzzy Set Theory and Its Applications. Boston, MA: Kluwer, 1996.

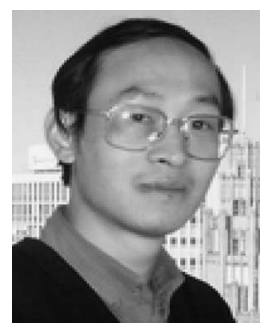

Hepu Deng received the B.S. degree in mathematics from Hunan Normal University, Changsha, China, the Postgraduate Diploma in management engineering from the University of Science and Technology Beijing, Beijing, China, and the M.S. and Ph.D. degrees in business systems from Monash University, Clayton, Australia

He is currently a Senior Lecturer with the School of Business Information Technology, RMIT University (formerly the Royal Melbourne Institute of Technology), Melbourne, Australia. He has published more than 40 refereed papers in prestigious international journals and conferences, in the areas of multicriteria analysis, approximate reasoning, preference modeling, intelligent systems, knowledge management, and their applications in business.

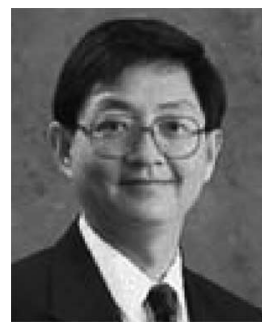

Chung-Hsing Yeh (M'97-SM'04) received the B.S degree in engineering and the Master of Management Science degree from National Cheng Kung University, Tainan, Taiwan, R.O.C., and the Ph.D. degree in information systems from Monash University, Clayton, Australia.

$\mathrm{He}$ is currently an Associate Professor with the Faculty of Information Technology, Monash University, Melbourne, Australia. He has published over 100 refereed papers in international journals and conferences in the areas of multicriteria decision analysis, fuzzy logic, intelligent systems, multilingual information processing, operations and production management, and transport research. 